\title{
Implementation of Target costing in the Saudi Arabian Food and Beverages Industry: The Mediating Role of Supply Chain Management
}

\author{
Hussein Hussein Hamood Sharaf-Addin* \\ Accounting Department, Faculty of Administrative Sciences, \\ Thamar University, Yemen
}

\begin{abstract}
Target Costing (TC) has been widely recognised by many organisations worldwide, but the inclusion of Supply Chain Management (SCM) when implementing TC is ambiguous. This study examined the implementation of TC through the mediation role of SCM based on the company strategies employed in the Saudi Arabian food and beverage industry. A questionnaire link was posted to 248 companies that were selected from a total of 791 companies, in which 186 responses were received and used for this study. The results revealed that the suppliers' participation had a significant mediating role in the relationship between price-based TC processes and TC financial and non-financial implications. Moreover, customers' inputs displayed a significant mediating role in the relationship between valuebased TC processes and TC financial and non-financial implications. Interestingly, these effects were found to be different among companies adopting the confrontation strategy and those adopting non-confrontation strategies, namely cost leadership and differentiation. This study addressed the significant gap in the literature regarding the mediating role of SCM when implementing the TC technique. From a methodological perspective, this study provides a new method of analysis that combines the use of the Rasch Measurement Model (RMM) and Structural Equation Modeling (SEM) for management accounting research.
\end{abstract}

Keywords: Target Costing, Supply Chain Management, Company Strategy, Food \& Beverages Industry

\section{ARTICLE INFO}

\section{Article History:}

Received: 1 June 2021

Accepted: 15 August 2021

Available online: 31 August 2021

\footnotetext{
*Corresponding Author: dr.hsharafi@gmail.com, Phone No.: +967773187159, Thamar University,
} Thamar 2153, Yemen 


\section{INTRODUCTION}

The primary focus of Target Costing (TC) is to sustain product competitiveness by sufficiently determining product cost, and its design and development, thus achieving the desired financial and non-financial objectives, respectively. TC can be viewed as a philosophy-based management system that includes cost control, profit management, value analysis, and value engineering (Sharaf-Addin et al., 2018). The implementation of TC in a highly complex supply chain market requires a more integrated effort compared to other management accounting techniques. It is vital for all supply chain partners to find ways to reduce costs in their design, manufacture, and distribution of components (Cooper \& Slagmulder, 1999) in order to achieve greater suppliers integration and hence supply chain performance (Jamal, Tayles, $\&$ Grant, 2019). Since achieving TC is a joint effort of the entire Supply Chain Management (SCM), the objectives of reaching the target cost must be understood and communicated effectively throughout the supply chain parties. However, the joint coordination needed to set an achievable TC is very time-consuming and requires the sharing of information related to the marketplace and cross-functional teamwork.

The initial process of asking suppliers for immediate cost savings is losing credibility and it has now become a widely accepted practice to share cost reduction in the long-term with suppliers by considering the inputs from customers. Therefore, the main objective of this study was to examine the mediating role of SCM in a company in the relationship between TC-based processes and implementation of TC. To achieve this objective, a survey of the Saudi Arabian food and beverage industry was drawn to provide empirical insights on implementation of TC. In a highly competitive environment, the food and beverage companies in Saudi Arabia produce a variety of products for both local and international markets. It was assumed for the purposes of this study that the TC technique could help companies to control and manage product costs at the early stages of production to improve their competitiveness.

The structure of the paper is as follows. Section 2 reviews previous studies and proceeds to the development of the hypotheses. Sections 3 outlines the methodology including survey design, data collection and analysis. Section 4 presents the empirical findings of the study. Finally, 
section 5 discusses these findings, provides a summary of the study, highlights the limitations and proposes areas for future research.

\section{LITERATURE REVIEW AND HYPOTHESES DEVELOPMENT}

\section{Target Costing and Supply Chain Management}

In $\mathrm{TC}$, product cost is an input in the product design process. When target costs are established by estimating the selling price of a product, the desired profit will be subtracted from the target costs (Horvath and Tani, 1997; Tani et al., 1994; Baharudin \& Jusoh, 2020). According to Cooper and Yoshikawa (1994), the purpose of TC is "to identify the production cost for a proposed product such that the product, when sold, generates the desired profit margin". Baharudin and Jusoh (2020) pointed out that the allowable cost is the cost at which the product must be produced to gain the targeted profit when sold at its targeted selling price. The Consortium for Advanced Manufacturing states that TC "represents a set of management tools and methods designed to direct design and planning activities for new products, provide a basis for controlling subsequent operational phases, and ensure that products achieve given profitability targets throughout their life cycle (Ansari \& Bell, 1997). The implementation of TC involves the following steps: (1) determine the market price, (2) identify the desired profit, (3) calculate the TC, (4) use value engineering to identify ways to reduce cost, (5) use continuous improvement and operational control for further cost reduction, and (6) work with suppliers to achieve the TC (Zbib et al., 2011). Therefore, these steps are crucial to ensure that the product design and the targeted costs achieve the targeted profit in line with customers' desires and suppliers' participation. Products that are produced with a high cost will face depression issues as customers will not be willing to pay. In other words, supply chain activities should be developed to ensure customers' desires, including product price are based on timely information (Doktoralina \& Apollo, 2019). Therefore, these two factors could play a vital role in determining product cost and features, and ultimately result in products that will meet customers' desires and achieve the targeted profit as well. 
Various definitions of SCM have been cited in the literature. According to Handfield (1999), the supply chain encompasses all activities associated with the flow of goods and transformation from the materials acquisition phase through to the successive steps leading up to the distribution of products to end-users. This includes all SCM-related activities that are associated with information sharing and transformation operations. Hence, a variety of resources and information throughout the production process are moving across the supply chain. Sharing accurate information with relative parties within the supply chain could be used as a source of competitive advantage (Jamal et al., 2019). According to Cokins (2002), cooperation with suppliers through the sharing of accurate cost accounting information in a supply chain network could enhance the level of trust with suppliers. Moreover, he noted that the overall costs can be lowered when all tiers in the chain understood their own costs and their partners' costs as well. However, Othman and Ghani (2008) indicated that the success of SCM depends on certain capabilities such as the organisations' flexibility, communication and coordination enhancement, and cost reduction. Therefore, skilled human resources as well as a wide network connection between the related departments are required. In addition, Pradhan et al. (2018) revealed that the adoption of management accounting techniques for supply chain activities was a suitable strategy to boost the performance of Indian companies. Similarly, Jamal et al. (2019) found a positive and significant relationship between management accounting practices and SCM practices among Malaysian public companies.

Previous studies have indicated that SCM plays a major role in the implementation of TC. In a study by Talha and Raja (2010), the substantive role of SCM appeared to be in the earlier stages of the production phase. The authors concluded that the involvement of SCM was crucial to identify and qualify good suppliers as well as influence the specifications of the major cost drivers for new products and services. Therefore, the role of SCM in TC is to identify capable suppliers to achieve customers' desires throughout the product development stages. According to Lockamy and Smith (2000), the implementation of TC requires information pertaining to a company's competitive advantage, product, and supply chain strategies. In addition, the close working relationship between SCM and design engineers to develop cost breakdowns is another important role of SCM in achieving success of TC (Ellram, 2002, 2006; Hamood et al., 2013a; Talha and Raja, 2010; 
Sharaf-Addin et al., 2018). This is because designers who fulfil suppliers' requirements have a direct impact on the estimated costs of products and services to meet the objectives of TC (Sharaf-Addin et al., 2018). Based on the findings by Ellram (2002), all the organisations investigated indicated that they worked with their key suppliers to help them improve their performance to meet TC goals. This included their participation in the design process of the materials, product components, and production process. Interestingly, he mentioned that the effective role of SCM was specifically related to managing the suppliers' relationship, time-to-market, cost management, and cost accountability.

Based on the above studies, the proposed illustration linking the implementation of TC with SCM activities is shown in Figure 1. Suppliers' participation and customers' inputs are encountered through the supply chain network. This observation was supported by Fayard et al. (2012) who revealed that organisations could achieve a competitive advantage based on customers' and suppliers' information shared through the supply chain.

\section{Supply Chain Network}

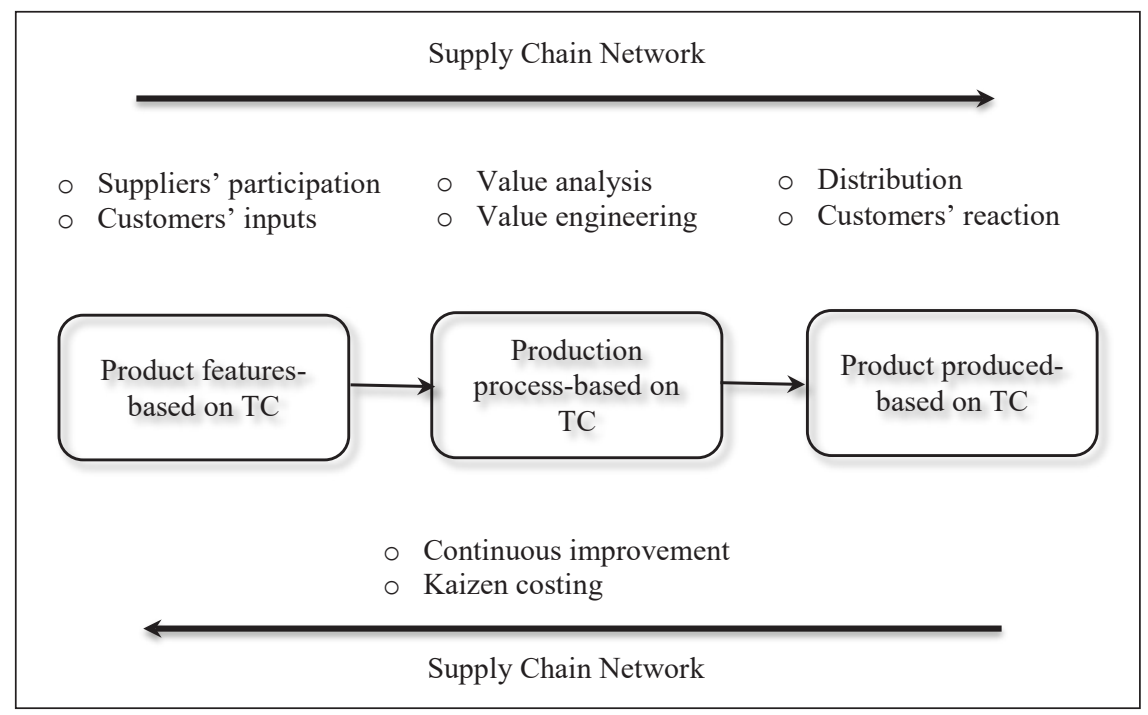

Figure 1: Linking Target Costing with Supply Chain Management

The key issue in SCM for implementation of TC is to design products that meet customers' desires and produce the products within the target costs. This is the initial process in which the product components can be 
developed based on a product's targeted price and features. Suppliers' contributions to achieve customers' desires in terms of product price and features should be involved across the supply chain (Jamal et al., 2019). It is therefore necessary for the supply chain to make a trade-off between product design requirements and end-users' desires. In some industries, supply chain performance is influenced by decisions such as "make or buy", "lease or buy", or "keep or replace" machines and equipment (Horvath \& Tani, 1997). In making these decisions, suppliers are given the expected demands of parts and components with specific features, and they will provide the estimated prices and time required for such demands to be fulfilled. This may affect the choices of new suitable suppliers to be involved in the supply chain and it may require existing suppliers to adjust their prices to fit in the target costs. In essence, suppliers are considered as strategic partners involved in TC processes (Celayir, 2020) and changing suppliers to fit the TCs should not compromise product quality (Awasthi, Nain, \& Roy, 2020). Meanwhile, TC activities are performed by obtaining market information, determining customers' desires (price, quality, and functionality), and finally going through a cross-functional team cooperation process. Therefore, TC could be a better choice for supply chains (Zbib et al., 2011) to make customers' requirements a top priority and maintain targeted profits for the company (Sharaf-Addin et al., 2018). Under TC, supply chain companies will incur only the necessary costs to satisfy the customers based on an acceptable price with the desired features (Smith and Lockamy, 2000). This finding supports the argument raised by Zbib et al. (2011) who indicated that TC integrates a company's internal design and processes with its external market requirements.

In an empirical study by Ellram (2006), a vital role of SCM for successful implementation of TC in US companies was established by working closely with suppliers to improve cost reductions and collect market data to assess suppliers' costs estimates. In their previous study, Ellram (2000) found that US companies had multiple objectives for implementation of TC which included cost reduction, understanding supplier's cost structures, improving internal cost management, improving cost monitoring, and increasing cost accountability. Following this, Ellram (2002) revealed that in some US case studies, suppliers played a significant role in offering new technology for product redesign to reduce costs. Moreover, the key role of purchasing was involved in the earlier stages of TC to ensure that 
products remained competitive when meeting customers' desires and market demands. Based on a study by Hamood et al., (2011), SCM plays a major role in linking TC objectives with customers' desires and market demands through the interactive involvement of suppliers in TC practices. Moreover, Sharaf-Addin et al. (2014) indicated that the involvement of SCM in TC practices as a main source of information was to ensure product value competitiveness. Zbib et al. (2011) revealed that the profitability of Honda Motors was a good indicator of TC success. The authors concluded that the SCM activities in TC practices forced the Honda Motors company to focus on cost efficiency, thus resulting in a $5 \%$ return on sales. In general, Talha and Raja (2010) reported that the Japanese TC system was supported by SCM through an aggressive commitment and continuous improvement of both the production processes and product value.

While Ellram (2006) observed that the SCM was working closely with its suppliers in developing cost breakdown activities when implementing TC in US companies, Hamood et al. (2013a) found that there was a lesser involvement of suppliers in implementation of TC among Malaysian companies. It was reported that the main challenges behind this observation were SCM and the relationship management practices that were employed to effectively manage the relationship with both customers and suppliers. This observation was consistent with the Romanian experience, whereby Briciu and Căpuşneanu (2013) identified issues pertaining to the close cooperation with supply chain partners.

In Saudi Arabia, the food and beverage industry is growing rapidly, and its local and international demands have been increasing yearly. This industry is one of the most attractive industries in the Middle East due to the massive growth in consumption, thus leading to a considerable growth in sales. Based on the annual report by the Saudi Arabian Monetary Authority (2018), the fund for food products was 1.8 billion SAR in 2018, accounting for $5.6 \%$ of the total funds of all the industries. The food and beverages product prices increased in 2018 to $7.6 \%$ compared to 2017 and the total exports of these products reached up to 13.798 billion in 2018 with a decrease in $3.5 \%$ compared to 2017 . This decline was due to certain economic factors that affected the food and beverage industry such as the increase in price of fuel, water, and electricity upon the implementation of the Value Added Tax (VAT) in 2017. Thus, these factors resulted in either 
a direct or indirect impact on production, transportation, and distribution costs. Hence, incentives were given to companies to reduce the total cost of products so that they could be sold at prices that the customers were willing to pay. In addition, the National Transformation Plan (NTP) proposed by the government encouraged private investment to enhance and diversify the total revenue of the country in accordance with the Kingdom's 2030 economic vision.

Therefore, it is necessary for Saudi manufacturing companies and particularly, food and beverage companies, to articulate their strategic plans based on market conditions to maintain their competitive advantage. TC could help these companies to reduce product cost while maintaining product quality. It will be interesting to see if companies are able to make a tradeoff between low cost and higher quality products upon the implementation of TC. However, little attention has been focused on the implementation of recent management accounting techniques such as TC in Saudi Arabia ${ }^{1}$. Only one study by Hammami, Al-Omiri, Bouraoui and Ousama (2019) was found, and the results confirmed that the Saudi Arabian manufacturing companies in general were interested to implement a TC system, and the intensity of competition positively affected the implementation of a TC system. Nevertheless, the inclusion of the effect of company strategies was ambiguous, focusing on cost leadership and differentiation strategies but ignoring the confrontation strategy, and the role of SCM was not investigated when implementing TC techniques.

\section{TC implementation through supply chain management}

To achieve the objectives of TC, SCM should perform follow-up activities on the increasing changes in customers' desires and maintain a long-term relationship with suppliers. These follow-up activities could play a vital role in pursuing the implementation objectives of TC that are related to product cost, design, and development. According to Cooper and Slagmulder (1997), there are two ways for cost reduction: (1) adopting accurate cost management systems, and (2) adopting modern technologies for product redesign. However, the second option is very useful for organisations implementing TC since a product's life-cycle cost is mostly determined during the design stage (Gopalakrishnan et al., 2007; Yalçın, 2011; Zengin $\&$ Ada, 2010). Huh et al. (2008) indicated that the information network

1 Most of the studies related to Saudi Arabia are generally focusing on financial accounting, corporate governance, auditing, and financial disclosure. 
among suppliers and customers was one of the dynamic capabilities related to the success of TC performance in Japanese companies. Recently, Pradhan et al. (2018) found a significant mediating effect of supply chain activities on the relationship between management accounting techniques and the financial performance of a firm. Meanwhile, Doktoralina and Apollo (2019) revealed a significant positive relationship between strategic management accounting practices and the profitability of Malaysian logistics firms that were mediated by supply chain outcomes.

Despite TC being one of the management accounting techniques examined in these studies, only organisational financial performance was evaluated and not TC performance. In addition, Smith and Lockamy (2000) indicated that a price-based TC approach depends on the supply chain activities in a business environment that maintains customers' requirements and long-run profitability. On the other hand, they reported that a value-based TC approach requires supply chains to match customers' changing desires by providing high-value products. In contrast, Baharudin and Jusoh (2020) found that the association between supplier relationship and successful implementation of TC was not supported in a Malaysian case study. Therefore, the study assumed that SCM is mainly focused on the integration of these two issues through the improvement of strategic relationships with both suppliers and customers to achieve a competitive advantage. Hence, it was proposed that the TC processes can be divided into two groups, whereby the first group was related to product pricing based on the targeted cost, and the other group was related to product value which included quality and functionality of the product based on the targeted cost. The following hypotheses were proposed:

H1a: Price-based TC processes have a positive and significant indirect effect on TC financial implications mediated by suppliers' participation

H1b: Price-based TC processes have a positive and significant indirect effect on TC non-financial implications mediated by suppliers' participation

H1c: Price-based TC processes have a positive and significant indirect effect on TC financial implications mediated by customers' inputs

H1d: Price-based TC processes have a positive and significant indirect effect on TC non-financial implications mediated by customers' inputs 
H2a: Value-based TC processes have a positive and significant indirect effect on TC financial implications mediated by suppliers' participation

H2b: Value-based TC processes have a positive and significant indirect effect on TC non-financial implications mediated by suppliers' participation

H2c: Value-based TC processes have a positive and significant indirect effect on TC financial implications mediated by customers' inputs

H2d: Value-based TC processes have a positive and significant indirect effect on TC non-financial implications mediated by customers' inputs

\section{Company Strategy}

Successful implementation of TC depends on company strategies that are based on the identification of the organisational functions (Tani et al., 1994; Tani, 1995). Hibbets et al. (2003) outlined three types of strategies that determine the decision to adopt TC in a commutative environment. It should be noted that company strategy can be a driving force for TC activities aimed towards achieving its objectives. According to Hibbets et al. (2003), company strategy includes information on the type of strategies employed by the company, namely, to produce products at a lower cost than competitors (Cost Leadership Strategy), produce products with unique features that are different from those of competitors (Differentiation Strategy), and produce products at lower costs and higher quality and functionality (Confrontation Strategy). For instance, Abdullah et al. (2006) indicated that the Proton's business strategies in Malaysia were cost leadership and differentiation strategies. Both these strategies were adopted through R\&D and outsourcing activities to access product development. Moreover, Sharaf-Addin et al. (2018) found cost leadership and differentiation strategies moderated the causal effect of organisational capabilities and decision-making on implementation of TC among Malaysian automotive companies. In contrast, Cooper (1995) indicated the suitability of the confrontation strategy for implementation of TC.

However, the differentiation strategy can be employed if customers were more confident in product quality. Hammami et al. (2019) found that the Saudi Arabian manufacturing companies employing a strategy were 
more inclined to implement TC than those employing the cost leadership strategy. On the other hand, maintaining product value and affordability is the primary focus of the confrontation strategy. The role of SCM in creating a trade-off between product cost, quality, and functionality as the focus of TC should be in line with company strategy. It should be noted that when implementing TC, company strategy should be used as a guide to control the TC-based processes by referring to the SCM members. Although SCM activities are essential when implementing TC, it is important to consider the company strategy as an additional influential factor rather than just a guide. In this study, company strategy was proposed as a control variable for the mediating role of SCM when implementing TC. Based on this proposition, it was assumed that the relationship between price-based and value-based TC processes and the implementation of TC mediated by the SCM is different according to the company strategy employed. Thus, the following hypothesis was developed:

H3: The mediating role of SCM in the relationship between TC-based processes and $\mathrm{TC}$ implementation is different according to the company strategy employed

However, only one study by Hibbets et al. (2003) regarding implementation of TC was found in the literature. In this study, the authors examined the relationship between the commutative environment and the decision to adopt TC that was moderated based on company strategy. Another recent study by Sharaf-Addin et al. (2018) examined the difference in the relationship between organisational capabilities and implementation of TC decisions across various types of company strategies. In the current research model, company strategy, including cost leadership, differentiation, and confrontation, was a control variable by which the relationship between TC-based processes and the financial and non-financial implications of implementation of TC was assessed through the mediating role of SCM including suppliers' participation and customers' inputs. 


\section{METHODOLOGY}

\section{Research Model and Variables Measurement}

The research model employed in this study was developed based on the economic framework proposed by Smith and Lockamy (2000) who indicated that the customers' inputs and suppliers' participation within the supply chains define TC processes. The model describes the indirect effect of TC processes on the financial and non-financial implications of TC through SCM controlled by company strategy. Figure 2 illustrates the research model developed in this study.

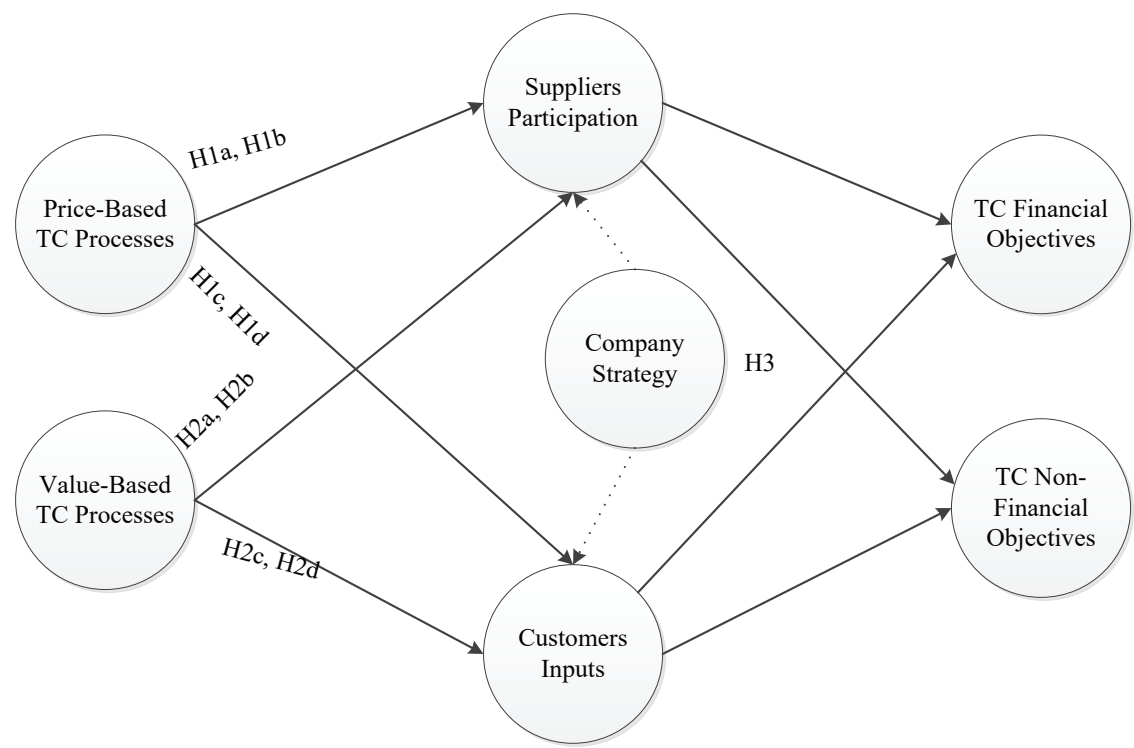

Figure 2: Empirical Research Model

In this model, the TC-based process was the independent variable, while the implementation of TC was the dependent variable. Additionally, SCM was the mediating variable and company strategy was the control variable. The measures of the independent, dependent, and mediating variables were adapted from the organisational complicity measures proposed by Huh et al. (2008), while company strategies were adapted from Hibbets et al. (2003). The independent variables include two variables, namely price-based TC processes and value-based TC processes. The price- 
based TC process variable was measured by Prce_CustWill, Prce_Compt, Prce_Qualt, Prce_Profit (see Appendix A). These measures were regarded as the main determinants of TC in relation to product price. Moreover, the value-based target cost variable was measured by VE, Tech_Rdsgn, TrdOff_Fear, Kzn_Cst (see Appendix A). These measures were regarded as the main determinants for TC in relation to product value.

On the other hand, implementation of TC as a dependent variable included the financial and non-financial implications of implementation of TC. It was classified in tandem with the two independent variables and thus measured using the Balanced Scorecard (BSC) perspectives including financial perspectives and non-financial perspectives (customer, internal process, and learning and growth). The measures of financial implications of TC included PrdCst_Rdct, RawMater_Rdct, Wast_Rdct, Tmly_TCachv (see Appendix A). In addition, the measures of non-financial implications of TC included Imprv_PrdctQu, ImprvDsgn_QuTech, Imprv_Funct, ImprvDsgn_FuncTech (see Appendix A). The SCM as a mediating variable in the model was measured by "suppliers' participation" and "customers' inputs" (SuppPartc, CustInputs, see Appendix A). Suppliers' participation as a mediating variable was measured by Sup_Feat, Sup_Prce, Spl_Rdsgn, Supl_Qual (see Appendix A). Customers' inputs as a mediating variable were measured by Cust_Expc, Rvew_Chng, Ftr_b4Dsgn, RD_Charct (see Appendix A). Company strategy, which was the control variable, was measured by the three types of strategies, namely "cost leadership", "differentiation", and "confrontation".

\section{Research Sample and Data Collection}

The food and beverage industry in Saudi Arabia was selected as the focus area for this study. The selection of this industry provided more incentives for the study on the implementation of TC as the TC practice has not been widely studied in Saudi Arabia. Moreover, there is a need for the food and beverage industry to find a way to control and manage product costs at the early stages of production when producing a variety of products. In total, 791 productive food and beverage companies identified from the Saudi Commercial and Industrial Directory (SCID) were selected as the study population. Based on the guidelines proposed by Krejcie and Morgan's (1970) table of sample size determinant ( $N=800, S=260$ ), only a 
total of 248 productive companies whose postal information was available were selected as the final sample size.

A postal questionnaire survey was conducted to collect the empirical data. The questionnaire was initially developed using a five-point Likert scale where " $1=$ Not Sure"; "5=Extremely Intense" with 24 questions (4 questions for each of the six construct variables, see Appendix A). The initial questions developed were tested via a pilot study on a sample of practitioners, and subsequently followed by an in-depth discussion with relevant managers and executives. The pilot data was analysed using the Rasch Measurement Model (RMM) to test the reliability and validity of the instruments and the tested questionnaire was further given to several colleagues to check the instrument developed.

Finally, the link for the final version of the questionnaire was sent to the target respondents. In the questionnaire, participants were informed that the target respondents were executives and officers who were working in the management and cost accounting departments, department managers, and general managers. The participants were also informed that the time given to respond to the questionnaire was one month, maximum. After six months, 184 completed questionnaires were received from all the selected companies that comprised food companies (35.4\%), food and Beverage companies (54.9\%), and beverages companies $(95.8 \%)$, with $75.1 \%$ of them being Saudi-owned companies. Furthermore, $69.9 \%$ of the companies were producing more than five products, and the majority of them (59.1.9\%) had both product parts and finished products as well as produced for both the local and international market (76.9\%) (Table 1). 
Table 1: Company Profiles

\begin{tabular}{|c|c|c|}
\hline Profile & Frequency & Percent \\
\hline \multicolumn{3}{|l|}{ Company Group: } \\
\hline Food products & 67 & 36.0 \\
\hline Food \& Beverage products & 92 & 49.5 \\
\hline Beverage products & 27 & 14.5 \\
\hline Total & 186 & 100.0 \\
\hline \multicolumn{3}{|l|}{ Product Types: } \\
\hline Parts & 36 & 19.4 \\
\hline Finished products & 40 & 21.5 \\
\hline Both & 110 & 59.1 \\
\hline Total & 186 & 100.0 \\
\hline \multicolumn{3}{|l|}{ Number of Products Produced: } \\
\hline $2-5$ products & 56 & 30.1 \\
\hline More than 5 products & 130 & 69.9 \\
\hline Total & 186 & 100.0 \\
\hline \multicolumn{3}{|l|}{ Product Market: } \\
\hline Local market & 43 & 23.1 \\
\hline Both & 143 & 76.9 \\
\hline Total & 186 & 100.0 \\
\hline \multicolumn{3}{|l|}{ Company Years of Establishment: } \\
\hline Less than 10 years & 10 & 5.4 \\
\hline $10-20$ years & 75 & 40.3 \\
\hline More than 20 years & 101 & 54.3 \\
\hline Total & 186 & 100.0 \\
\hline \multicolumn{3}{|l|}{ Ownership Structure: } \\
\hline Saudi-owned & 139 & 75.1 \\
\hline Foreign-owned & 8 & 4.3 \\
\hline Joint venture & 39 & 20.5 \\
\hline Total & 186 & 100.0 \\
\hline \multicolumn{3}{|l|}{ Company Strategy: } \\
\hline Cost leadership strategy & 18 & 8.1 \\
\hline Differentiation strategy & 46 & 26.3 \\
\hline Confrontation strategy & 122 & 65.6 \\
\hline Total & 186 & 100.0 \\
\hline
\end{tabular}




\section{Data Analysis}

Two statistical analysis methods, namely the Rasch Measurement Model (RMM) and Structural Equation Modeling (SEM) were used in this study. Firstly, a pilot data analysis was performed using the RMM to test the reliability and validity of instruments. Further tests of reliability and validity were also conducted for the final study using the RMM as well. Based on the statistical reliability and validity generated by the RMM, the SEM model was built. The results revealed an acceptable reliability value (Cronbach's alpha $=0.87$ ), which was more than the minimum of 0.70 according to Fisher (2007), thus indicating that the items under each variable were measuring a single construct. The Fit Statistics and Principle Component Analysis for all the items measuring each construct variable are shown in Table 2. The variance explained by the measures for each construct variable fitted well with the modelled data, while the unexpected variance explained in the first contrast for each construct variable was less than the modelled data. These results confirmed the inclusion of all items under each construct variable for further analysis.

Table 2: Standardised Residual Variance (in Eigenvalue units)

\begin{tabular}{lcccc}
\hline & \multicolumn{2}{c}{$\begin{array}{c}\text { Raw variance explained } \\
\text { by measures }\end{array}$} & $\begin{array}{c}\text { Unexplained variance } \\
\text { in 1 }\end{array}$ \\
\cline { 2 - 5 } & Empirical & Modelled & Empirical & Modelled \\
\hline Price-Based TC & $31.2 \%$ & $31.2 \%$ & $6.8 \%$ & $9.6 \%$ \\
Value-Based TC & $34.9 \%$ & $35.3 \%$ & $7.1 \%$ & $10.4 \%$ \\
Suppliers' Participation & $30.1 \%$ & $32.4 \%$ & $8.5 \%$ & $10.3 \%$ \\
Customers' Inputs & $31.6 \%$ & $34.8 \%$ & $7.2 \%$ & $9.9 \%$ \\
Financial Implications of TC & $33.7 \%$ & $33.9 \%$ & $9.5 \%$ & $9.8 \%$ \\
Non-Financial Implications of TC & $48.5 \%$ & $48.8 \%$ & $9.9 \%$ & $10.2 \%$
\end{tabular}

Following the RMM analysis, the SEM analysis using AMOS Graphics version 22 was performed to test the hypotheses. The structural model in SEM was specified directly using path analysis and group variance analysis, in which all construct variables were modelled and the indirect relationship between variables was estimated. The Goodness-of-Fit (GOF) indicators for the structural model were verified using the Comparative Fit Index (CFI), Root Mean Squared Residual (RMR), and Root Mean Squared Approximation of Error (RMSEA) that were considered as 
important indices for GOF (Awang, 2012). However, these indices should be $\mathrm{CFI}>.90, \mathrm{RMR}<.09$ and RMSEA $<.09$ for any sample size with more than 150 respondents (Awang, 2012; Byrne, 2010; Hair, 2010). It was noted through the final outputs of the SEM structural model that these requirements were slightly fulfilled. The RMSEA value was 0.090 and the RMR value was 0.065 , while the CFI value of 0.783 was less than 0.90 . However, this value did not affect the discrepancy between the estimated and observed constructs (Awang, 2012).

In addition, many of the factor loadings exceeded the value of 0.50 and matched the optimal value suggested by Hair (2010) and Byrne (2010), except for three items. Nevertheless, for this study, all the items were included in the analysis. Therefore, these results supported the model fit, in which the relationships between variables were assumed since there was less discrepancy between the observed and estimated constructs. However, after model fit assessment, the model was run to test the mediation effect for each variable of the SCM separately, as well as the direct relationship either with or without the mediation effect was estimated to determine the mediation type, following Awang (2012) and Hair (2010).

\section{RESULTS}

\section{Price-Based TC Processes and Target Costing Implementation}

The results as Table 3 display the path coefficients for the structural constructs of price-based TC processes and both dimensions of TC implementation including financial and non-financial implications. All the direct beta coefficients with and without the mediation role of SCM as well as the indirect beta coefficients are shown in Table 3. 
Table 3: Results of Price-Based TC Processes through the Mediation Role of SCM

\begin{tabular}{|c|c|c|c|c|}
\hline Hypotheses & $\begin{array}{c}\text { Direct } \\
\text { Beta with } \\
\text { Mediation }\end{array}$ & $\begin{array}{c}\text { Direct Beta } \\
\text { without } \\
\text { Mediation }\end{array}$ & $\begin{array}{l}\text { Indirect } \\
\text { Beta }\end{array}$ & $\begin{array}{l}\text { Mediation Type } \\
\text { Observed }\end{array}$ \\
\hline $\begin{array}{l}\text { H1a: PrceBasedTC } \rightarrow \text { SupPartc } \rightarrow \\
\text { Financlmplic }\end{array}$ & $.250(.156)$ & $.178(.134)$ & $.092(.033)$ & Sig - Part Med \\
\hline $\begin{array}{l}\text { H1b: PrceBasedTC } \rightarrow \text { SupPartc } \rightarrow \\
\text { Non-Financlmplic }\end{array}$ & $.205(.100)$ & $.218(.139)$ & $.087(.040)$ & Sig - Part Med \\
\hline $\begin{array}{l}\text { H1c: PrceBasedTC } \rightarrow \text { Custlnputs } \rightarrow \\
\text { FinancImplic }\end{array}$ & $.118(.325)$ & $.178(.134)$ & $.090(.152)$ & NS - No Med \\
\hline $\begin{array}{l}\text { H1d: PrceBasedTC } \rightarrow \text { Custlnputs } \rightarrow \\
\text { Non-Financlmplic }\end{array}$ & $.181(.147)$ & $.218(.139)$ & $.086(.258)$ & NS - No Med \\
\hline
\end{tabular}

As shown in Table 3, the indirect relationship of price-based TC processes and financial implications of implementation of TC mediated by suppliers' participation was positive and significant (Beta $=.092$; and $P<.05$ ) (Hypothesis 1a was accepted). In addition, the indirect relationship of price-based TC processes and non-financial implications of implementation of TC mediated by suppliers' participation was positive and significant $($ Beta $=.087 ; P<.05)$ (Hypothesis $1 \mathrm{~b}$ was accepted). Since the direct beta coefficients with and without the mediation effect of suppliers' participation were not significant, the type of mediation observed was partial mediation (Awang, 2012). On the other hand, the indirect relationship of price-based TC processes and both the financial and non-financial implications of implementation of TC mediated by customers' inputs was positive but not significant $(B e t a=.090, .086 ; P>.05)$ (Hypotheses $1 \mathrm{c}$ and $1 \mathrm{~d}$ were rejected).

\section{Value-Based TC Processes and Target Costing Implementation}

Table (4) shows the path coefficients for the structural constructs of value-based TC processes and both dimensions of implementation of TC including financial and non-financial implications. All the direct beta coefficients with and without the mediation role of SCM as well as the indirect beta coefficients are presented in Table 4 . 
Table 4: Results of Value-Based TC Processes through the Mediation Role of SCM

\begin{tabular}{|c|c|c|c|c|}
\hline Hypotheses & $\begin{array}{l}\text { Direct Beta } \\
\text { with Mediation }\end{array}$ & $\begin{array}{l}\text { Direct Beta } \\
\text { without } \\
\text { Mediation }\end{array}$ & $\begin{array}{l}\text { Indirect } \\
\text { Beta }\end{array}$ & $\begin{array}{c}\text { Mediation } \\
\text { Type } \\
\text { Observed }\end{array}$ \\
\hline $\begin{array}{l}\text { H2a: ValueBasedTC } \rightarrow \text { SupPartc } \rightarrow \\
\text { Financlmplic }\end{array}$ & $.354(.054)$ & $.240(.068)$ & $.096(.053)$ & NS - No Med \\
\hline $\begin{array}{l}\text { H2b: ValueBasedTC } \rightarrow \text { SupPartc } \rightarrow \\
\text { Non-FinancImplic }\end{array}$ & $.392(.100)$ & $.336(.047)$ & $.150(.020)$ & Sig - Part Med \\
\hline $\begin{array}{l}\text { H2c: ValueBasedTC } \rightarrow \text { Custlnputs } \rightarrow \\
\text { Financlmplic }\end{array}$ & $.025(.000)$ & $.240(.068)$ & $.268(.006)$ & Sig - Part Med \\
\hline $\begin{array}{l}\text { H2d: ValueBasedTC } \rightarrow \text { Custlnputs } \rightarrow \\
\text { Non-Financlmplic }\end{array}$ & $.190(.027)$ & $.336(.047)$ & $.286(.011)$ & Sig - Full Med \\
\hline
\end{tabular}

From the results in Table 4, it can be observed that the indirect relationship of value-based TC processes and financial implications of TC implementation mediated by suppliers' participation was positive but not significant (Beta $=.096, P>.05$ ) (Hypotheses $2 \mathrm{a}$ was rejected). In contrast, the indirect relationship of value-based TC processes and non-financial implications of TC implementation mediated by suppliers' participation was positive and significant $($ Beta $=.150, P<.05)$ (Hypotheses $2 \mathrm{~b}$ was accepted). Although the direct relationships with the mediation effect of suppliers' participation for non-financial TC implications were not significant (Beta $=.392, \mathrm{P}>.05)$, the relationship with the mediating effect was significant $(\mathrm{Beta}=.336, \mathrm{P}<.05)$ and hence, the type of mediation observed was partial mediation. On the other hand, the indirect relationship of value-based TC processes and financial implications of TC implementation mediated by customers' inputs was positive and significant $($ Beta $=.268 ; P<.05)$ (Hypotheses 2c was accepted).

Although the direct relationship with the mediating effect of customers' inputs was significant (Beta $=.025, P<.05)$, the direct relationship without the mediating effect was not significant $($ Beta $=.240, P>.05)$ and hence, the type of the mediation observed was partial mediation. Nevertheless, the only full mediation effect observed was for customers' inputs in the indirect relationship between value-based TC processes and non-financial implications of implementation of TC, whereby both direct relationships with and without the mediation effect were significant (Beta $=.190, .336$ respectively; $P<.05)$. Accordingly, the indirect relationship observed was positive and significant $($ Beta $=.286 ; \mathcal{P}<.05)$ (Hypotheses $2 \mathrm{~d}$ was accepted). 


\section{Company Strategy in the Mediation Role of SCM}

It was proposed that the company strategy used by the companies in this study was the source of difference for the indirect effect of price-based and value-based target costs for both financial and non-financial TC implications. The structural invariance of the model was tested across the three types of company strategies, namely cost leadership $(n=18)$, differentiation $(n=46)$, and confrontation $(\mathrm{n}=122)$. Based on the recommendations by Sharaf-Addin et al. (2018), the first two strategies were combined for the analysis, thus resulting in two main groups consisting of the confrontation strategy $(n=122)$ and non-confrontation strategy $(n=64)$. Both these groups were analysed using the Group Invariance Analysis. The factor loadings invariance was analysed together with the latent means differences test of price-based and value-based TC processes (Byrne, 2010). Next, the invariance of the structural path (TC processes $\rightarrow \mathrm{SCM} \rightarrow \mathrm{TC}$ implications) was tested in the unconstrained model using the company strategy invariance and showed a baseline Chi-square value. Finally, the invariance of the same structural path was tested in the constrained model and was found to be equal across both groups of strategies. Meanwhile, the mean of the latent construct in the same structural paths for the confrontation strategy group was constrained to zero as a reference of differences. This was consistent with Cooper's (1995) argument that the confrontation strategy is recommended for implementation of TC. Table 5 shows the invariance test results across both groups at the full model level.

Table 5: The Full Model Results Associated with Company Strategy Invariance

\begin{tabular}{|c|c|c|c|c|c|c|c|c|}
\hline Model Description & $x^{2}$ & df & $\begin{array}{l}\text { Critical } \\
\text { Value }\end{array}$ & $\Delta \mathbf{x}^{2}$ & df & $p$-value & CFI & $\Delta \mathrm{CFI}$ \\
\hline $\begin{array}{l}\text { Unconstrained model, } \\
\text { no equality constraints }\end{array}$ & 921.899 & 441 & - & - & - & - & .740 & - \\
\hline $\begin{array}{l}\text { Constrained model, } \\
\text { with equality constraints }\end{array}$ & 958.318 & 472 & 49.48 & 36.419 & 31 & $* * *$ & .751 & .011 \\
\hline
\end{tabular}

As shown in Table 5, there was a significant change in the Chi-square value $\left(\Delta \chi^{2}(31)=76.419, P\right.$-value $\left.<0.005\right)$, which was less than the critical value of 49.48 with 31 degrees of freedom (Byrne, 2010). Although there was no significant change in $\mathrm{CFI}(\triangle \mathrm{CFI}=0.011, P$-value $>0.05)$, the higher 
change observed in $\chi^{2}$ values provided sufficient evidence (Byrne, 2010). Hence, the significant $\chi^{2}$ change was enough to indicate that the two groups were different at the full model level (Hypothesis 3 was accepted).

However, to determine which factor loading parameters of pricebased and value-based TC processes were different across both groups, further analysis of SCM factors was performed. All factors for suppliers' participation were analysed and followed by all the factors for customers' inputs. The results are presented in Table 6, whereby both groups were found to have non-invariance for the suppliers' participation since the change in Chi-square between the constrained and unconstrained models was significant. The difference was less than the critical value of 44.46 with 28 degrees of freedom $\left(\chi^{2}(28)=36.794, P\right.$-value $\left.<0.005\right)$.

Table 6: The Invariance Results Associated with Suppliers' Participation

\begin{tabular}{lcccc}
\hline & $\begin{array}{c}\text { Constrained } \\
\text { Model }\end{array}$ & $\begin{array}{c}\text { Unconstrained } \\
\text { Model }\end{array}$ & Differences & Results \\
\hline Chi-Square & 978.391 & 941.597 & 36.794 & $* * *$ \\
DF & 492 & 464 & 28 & \\
CFI & .694 & .681 & .013 & \\
\hline
\end{tabular}

Note: Significance level at ${ }^{* \star *} \mathrm{p}<0.005$ (two-tailed)

The model was retained and the invariance test for the customers' inputs factor loadings was performed. Surprisingly, the results revealed that there was no significant change in the Chi-Square value between the two groups $\left(\Delta \chi^{2}(19)=69.187, P\right.$-value $\left.>0.005\right)($ Table 7$)$, in which the change was found to be more than the critical value of 32.85 with 19 degrees of freedom (Byrne, 2010).

Table 7: The Invariance Results Associated with Customers' Inputs

\begin{tabular}{lcccc}
\hline & $\begin{array}{c}\text { Constrained } \\
\text { Model }\end{array}$ & $\begin{array}{c}\text { Unconstrained } \\
\text { Model }\end{array}$ & Differences & Results \\
\hline Chi-Square & 971.568 & 902.381 & 69.187 & 0.271 \\
DF & 491 & 472 & 19 & \\
CFI & .633 & .618 & .015 & \\
\hline
\end{tabular}

Note: Significance level at ${ }^{* \star *} \mathrm{p}<0.005$ (two-tailed)

Therefore, it can be concluded that the non-invariance issue between both the confrontation strategy and non-confrontation strategy groups lies 
within the factor parameters in the suppliers' participation but not the factors associated with customers' inputs.

\section{DISCUSSION AND CONCLUSION}

The findings of this study generally affirm the previous studies indicating that SCM can support TC processes (Helms et al., 2005; Lockamy and Smith, 2000; Smith and Lockamy, 2000; Talha and Raja, 2010; Sharaf-addin et al., 2018; Hammami et al., 2019). However, there is no evidence in the literature supporting the mediating role of SCM when implementing the TC techniques. More specifically, the findings of this study provide empirical evidence of the mediating role of both the factors of SCM which include suppliers' participation and customers' inputs. The TC techniques focus on the product costs, quality, and functionality, which ultimately depend on the company strategy employed. Hence, the mediating role of SCM is expanded to include the control effect of the company strategy which subsequently, determines the company policy aimed towards customer value creation as a part of TC implementation. This is somewhat consistent with the argument raised by Helms et al. (2005) who indicated that the cost information related to product value should be shared with cooperating companies in an open information network.

Unlike previous studies (e.g. Lockamy and Smith, 2000; Ellram, 2002, 2006; Hamood et al., 2013a; Huh et al., 2008; Sharaf-Addin et al., 2018), the understanding of the TC concept as price-based TC processes based on the customers' expectations is not well understood by Saudi Arabian companies. This scenario occurs as there is no mediating role of customers' inputs in the relationship between price-based TC processes and both the financial and non-financial TC implications. The only significant mediation role found in the relationship between price-based TC processes and both the financial and non-financial TC implications is the one related to suppliers' participation. Hence, it is evident that the Saudi Arabian food and beverage companies slightly prefer to use e traditional pricing methods or consider the TC concept as a cost-based technique. On the other hand, these findings offer the assurance that the price determination of products together with the activities related to product costs are shared among the suppliers, but not with customers. 
Consistent with this finding, Awasthi et al. (2020) found that the Indian food and beverage companies change suppliers for product cost cutting instead of compromising product quality. Moreover, the findings revealed a significant mediating role of SCM in the relationship between value-based TC processes and both implications of implementation of TC, except for TC financial implications in the mediation role of suppliers' participation. This result supports the earlier findings indicating that the food and beverage companies did not determine product prices based on suppliers' participation. The significant mediating role of value-based TC processes in the non-financial implications of implementation of TC was consistent with the confrontation strategy suggested by Cooper (1995) and affirmed by Sharaf-Addin et al. (2018) and Hammami et al. (2019). This finding is substantiated as there was a significant difference between companies employing the confrontation strategy and non-confrontation strategy (cost leadership and differentiation strategies) in the mediating role of suppliers' participation but not for customers' inputs.

However, this observation is inconsistent with the findings by Hamood et al. (2013b) and Sharaf-Addin et al., (2018) who indicated that both groups of Malaysian automotive companies were different based on all the SCM factors investigated. The nature of production activities between both the industries may lead to differences in the role of suppliers' participation in price-based TC processes as automotive companies depend highly on parts and components produced by their suppliers. This trend was also observed in most of the sampled food and beverage companies (59.1\%) who were producing parts and finished products (Table 1). Only one similar study by Attia and Essam Eldin (2018) revealed a significant effect of knowledge management capabilities and SCM practices on organisational performance in Saudi Arabian food companies. In this study, the knowledge management capabilities positively affected SCM activities, while the latter affected the organisational performance.

In this study, TC implementation through the mediating role of SCM measured by suppliers' participation and customers' inputs was analysed and an empirical research model was developed based on the study by Sharaf-addin et al. (2018) and the economic framework proposed by Smith and Lockamy (2000). The model depicted the indirect relationships between price-based and value-based TC processes and the objectives 
of implementation of TC through the mediating role of SCM controlled by company strategy. In total, three main hypotheses and eight subhypotheses under the first two hypotheses were proposed in this study. The first hypothesis consisted of four sub-hypotheses that tested the indirect relationships between price-based TC processes and both financial and nonfinancial implications of implementation of TC through the mediation role of SCM. For this hypothesis, the first two sub-hypotheses were supported, indicating that there was a partial mediating role of suppliers' participation in the relationship between price-based TC processes and objectives of implementation of TC including financial and non-financial implications. However, the remaining two sub-hypotheses were rejected, thus indicating that there was no mediating role of customers' inputs in the relationship between price-based TC processes and both the TC implications.

Similarly, the second hypothesis consisted of four sub-hypotheses that were related to value-based TC processes. All the hypotheses were supported except for the first sub-hypothesis which indicated that there was no mediating role of suppliers' participation in the relationship between value-based TC processes and the financial implications of implementation of TC. The remaining three hypotheses were supported based on different mediation types. The second sub-hypothesis revealed a significant partial mediating role of suppliers' participation in the relationship between valuebased TC processes and non-financial objectives of implementation of TC. This finding indicates that suppliers' participation played a major role in creating product value during implementation of TC to achieve the nonfinancial objectives of TC. Although another significant partial mediating role was observed for customers' inputs in the third sub-hypothesis, the full mediating role of customers' inputs was observed only in the fourth subhypothesis. These findings provide evidence that customers' inputs play a vital mediating role in value-based TC processes in implementation of TC to achieve both financial and non-financial TC implications.

On the other hand, the third hypothesis was developed to test the difference between companies that employed the confrontation strategy and non-confrontation strategy (cost leadership and differentiation) as a mediating role when implementing TC. The findings revealed a significant difference in both groups of companies, whereby differences were exhibited for all SCM factors. Further findings also provide evidence that the 
difference was based on suppliers' participation factors but not customers' inputs factors. Therefore, this finding provides support for the role of SCM in network sharing and the use of the confrontation strategy when implementing TC.

Based on the empirical findings of this study, the knowledge on the mediating role of SCM in implementation of TC is further expanded following previous studies such as those by Sharaf-Addin et al. (2018) as relevant studies on this topic are almost non-existent. This study provides empirical evidence on TC-related processes and the objectives of implementation of TC through the mediating role of SCM in Saudi Arabia compared to other studies that have only focused on the implementation rate of TC among other management accounting techniques. From a methodological perspective, this study provides a new statistical analysis technique that can be employed in management accounting research, whereby RMM was used to test the reliability and validity of the developed variables in the study. Nevertheless, despite the significant contribution of this study, several limitations need to be addressed. Using the electronic form of questionnaire, only participants who could access the internet were able to participate in the questionnaire survey, thus leading to a small sample. Moreover, whilst the selection of the food and beverages industry was suitable for this study as it was one of the largest industries in Saudi Arabia, the huge operational difference between food companies and beverage companies may present certain complexities for the findings. Therefore, future research should be conducted on a single industry to identify specific organisational capabilities that could lead to meaningful results.

\section{REFERENCES}

Abdullah, R., Lall, M.K., Tatsuo, K. (2008). Supplier development framework in the Malaysian automotive industry: Proton's experience. International Journal of Economic Management. 2(1), 29-58.

Ansari, S. L., \& Bell, J. E. (1997). The CAM-I Target Cost Core Group (1997), Target Costing: The Next Frontier in Strategic Cost Management. A CAM-I/CMS Model for Profit Planning and Cost Management, IRWIN, McGraw Hill, New York. 
Attia, A., \& Essam Eldin, I. (2018). Organizational learning, knowledge management capability and supply chain management practices in the Saudi food industry. Journal of Knowledge Management, 22(6), $1217-1242$.

Awang, Z. (2012). Structural equation modeling using AMOS graphic. Penerbit Universiti Teknologi MARA.

Awasthi, A., Nain, A., \& Roy, A. (2020). A study on cost cutting \& control in food \& beverage service department. International Journal of Scientific and Technology Research, 9(2), 1717-1719.

Baharudin, N., \& Jusoh, R. (2020). Enablers of Target Cost Management Implementation: Evidence from Malaysia. Jurnal Dinamika Akuntansi Dan Bisnis, 7(1), 87-106.

Briciu, S., Căpuşneanu, S. (2013). Pros and cons for the implementation of target costing method in Romanian economic entities. Accounting and Management Information Systems, 12(3), 455-470.

Byrne, B. M. (2010). Structural equation modeling with AMOS: Basic concepts, applications, and programming (Second Edi.). Routledge.

Celayir, D. (2020). Target Costing as a Strategic Cost Management Tool and a Survey on Its Implementation in the Turkish Furniture Industry. Journal of Business Research - Turk, 12(2), 1308-1321.

Cokins, G. (2002). Integrating target costing and ABC. Journal of Cost Management, 16(4), 13-22.

Cooper, R. (1995). When lean enterprises collide: competing through confrontation. Harvard Business Press.

Cooper, R., \& Slagmulder, R. (1997). Target costing and value engineering. Productivity Press Portland.

Cooper, R., \& Slagmulder, R. (1999). Develop Profitable New Products with Target Costing. Sloan Management Review, 40(4), 23. 
Cooper, R., \& Yoshikawa, T. (1994). Inter-organizational cost management systems: The case of the Tokyo-Yokohama-Kamakura supplier chain. International Journal of Production Economics, 37(1), 51-62.

Doktoralina, C. M., \& Apollo. (2019). The contribution of strategic management accounting in supply chain outcomes and logistic firm profitability. Uncertain Supply Chain Management, 7(2), 145-156.

Ellram, L. (2006). The implementation of target costing in the United States: theory versus practice. Journal of Supply Chain Management, 42(1), pg. 13.

Ellram, L. M. (2000). Purchasing and Supply M anagement's Participation in the Target Costing Process. Journal of Supply Chain Management, 36(2), 39-51.

Ellram, L. M. (2002). Supply management's involvement in the target costing process. European Journal of Purchasing and Supply Management, 8(4), 235-244.

Fayard, D., Lee, L. S., Leitch, R. a., \& Kettinger, W. J. (2012). Effect of internal cost management, information systems integration, and absorptive capacity on inter-organizational cost management in supply chains. Accounting, Organizations and Society, 37(3), 168-187.

Gopalakrishnan, B., Kokatnur, a., \& Gupta, D. P. (2007). Design and development of a target-costing system for turning operation. Journal of Manufacturing Technology Management, 18(2), 217-238.

Hair, J. F. (2010). Multivariate Data Analysis (7th Ed.). New Jersey: Prentice Hall.

Hammami, H., Al-Omiri, M., Bouraoui, T., \& Ousama, A. A. (2019). Target Costing: Adoption and Its Relationships With CompetitionIntensity, Intended Strategy and Firm Size. Asia-Pacific Management Accounting Journal, 14(3), 219-245. 
Hamood, H. H., Omar, N., \& Sulaiman, S. (2011). Target costing practices: A review of literature. Asia-Pacific Management Accounting Journal, 6(1), 25-46.

Hamood, H., Omar, N., \& Sulaiman, S. (2013a). Target Costing Implementation and Organizational Capabilities: A Research Framework. Asia-Pacific Management Accounting Journal, 8(2), 47-62.

Hamood, H. H., Omar, N., \& Sulaiman, S. (2013b). Target Costing Implementation in Malaysian Automotive Industry: An Exploratory Study. Asia-Pacific Management Accounting Journal, 8(1), 19-48.

Handfield, R. (1999). Involving Suppliers in New Product Development. Caufornia Management Review, 42(I), 59-82.

Helms, M. M., Ettkin, L. P., Baxter, J. T., \& Gordon, M. W. (2005). Managerial implications of target costing. Competitiveness Review: An International Business Journal Incorporating Journal of Global Competitiveness, 15(1), 49-56.

Hibbets, A., Albright, T., \& Funk, W. (2003). The competitive environment and strategy of target costing implementers: evidence from the field. Journal of Managerial Issues, 15(1), 65-81.

Horvath, P., \& Tani, T. (1997). Japanese-German comparison of target costing management. In the 1997 EAA Congress. Graz.

Huh, S., Yook, K., \& Kim, I. (2008). Relationship between organizational capabilities and performance of target costing: An empirical study of Japanese companies. Journal of International Business Research, 7(1), 91-108.

Jamal, N. M., Tayles, M., \& Grant, D. B. (2019). Investigating the Relationship Between Supply Chain Management and Management Accounting Practices. Journal of Supply Chain Management: Research \& Practice, 13(2), 1-22. 
Krejcie, R. V, \& Morgan, D. (1970). Determining sample size for research activities. Educational and Psychological Measurement, 30(3), 607-610.

Lockamy, A., \& Smith, W. I. (2000). Target costing for supply chain management: Criteria and selection. Industrial Management and Data Systems, 100(5), 210-218.

Othman, R., \& Ghani, R. A. (2008). Supply chain management and suppliers' HRM practice. Supply Chain Management: An International Journal, 13(4), 259-262.

Pradhan, D., Swain, P. K., \& Dash, M. (2018). Effect of management accounting techniques on supply chain and firm performance - an empirical study. International Journal of Mechanical Engineering and Technology, 9(5), 1049-1057.

Saudi Arabian Monetary Authority, 2018. 54th Annual Report 2018. Saudi Arabian Monetary Authority, Saudi Arabia.

Sharaf-Addin, H. H., Omar, N., \& Sulaiman, S. (2014). Target Costing Evolution: A Review of the Literature from IFAC's (1998) Perspective Model. Asian Social Science, 10(9), 82-99.

Sharaf-Addin, H. H., Omar, N., \& Sulaiman, S. (2018). Relationship between Organizational Capabilities, Implementation Decision on Target Costing and Organisational Performance : An Empirical Study of Malaysian Automotive Industry. Pertanika J. Soc. Sci. \& Hum., 26(2), 615-642.

Smith, W. I., \& Lockamy, A. (2000). Target costing for supply chain management: An economic framework. Journal of Corporate Accounting \& Finance, 12(1), 67-77.

Talha, M., \& Raja, J. B. (2010). Role of supply chain management in target costing. Journal of Modern Accounting and Auditing, 6(7), 46-58.

Tani, T. (1995). Interactive control in target cost management. Management Accounting Research, 6, 399-414. 
Tani, T., Okano, H., Shimizu, N., Iwabuchi, Y., Fukuda, J., \& Cooray, S. (1994). Target cost management in Japanese companies: current state of the art. Management Accounting Research, 5(1), 67-81.

Yalçın, S. (2011). Customer Focused New Product Design Process Using Target Costing and Quality Function Deployment. Middle Eastern Finance and Economics, 11(11), 118-131.

Zbib, I. J., Rakotobe-Joel, T., \& Rigoli, R. (2011). Target Costing : The Key To Supply Chain Excellence. International Business \& Economics Research Journal, 2(11), 27-34.

Zengin, Y., \& Ada, E. (2010). Cost management through product design: target costing approach. International Journal of Production Research, 48(19), 5593-5611. 


\section{APPENDIX}

\section{Appendix A: Measurement Instruments}

\begin{tabular}{ll}
\hline PrceBased & price-based TC processes \\
ValueBased & value-based TC processes \\
Custlnputs & customers inputs \\
SuppPartc & suppliers participation \\
NonFinclmplc & TC non-financial implication \\
FincImplc & TC financial implication \\
Cust_Expc & customers expectations \\
Rvew_Chng & review market changes \\
Ftr_b4Dsgn & product feature determination before design \\
RD_Charct & research and development \\
Supl_Qual & suppliers participation in product quality \\
Spl_Rdsgn & suppliers participation in product re-design \\
Sup_Prce & suppliers participation in product price \\
Sup_Feat & suppliers participation in product features \\
ImprvDsgn_FuncTech & improve design to functionality technology \\
Imprv_Funct & improve product functionality \\
ImprvDsgn_QuTech & improve design to quality technology \\
Imprv_PrdctQu & improve product quality \\
Tmly_TCachv & timely achievement of cost reduction \\
Wast_Rdct & waste reduction \\
RawMater_Rdct & raw materials reduction \\
PrdCst_Rdct & product cost reduction \\
VE & value engineering \\
Tech_Rdsgn & new technology related to product re-design \\
TrdOff_Fear & trade-off between features and cost breakdowns \\
Kzn_Cst & kaizen costing \\
Prce_CustWill & price that the customers are willing to pay \\
Prce_Compt & price compared to competitors' price \\
Prce_Qualt & price that achieves quality \\
Prce_Profit & price that achieves functionality \\
\hline &
\end{tabular}

